\title{
O DESENHO COMO RECURSO DIDÁTICO NO ENSINO DE GEOGRAFIA
}

\author{
Thiago Calheiros Dantas \\ Universidade Federal de Alagoas, Instituto de Geografia, Desenvolvimento e Meio Ambiente, \\ Maceió, AL, Brasil \\ thiagocalheirosdantas@gmail.com \\ Maria Francineila Pinheiro dos Santos \\ Universidade Federal de Alagoas, Instituto de Geografia, Desenvolvimento e Meio Ambiente, \\ Maceió, AL, Brasil \\ francineila.pinheiro@igdema.ufal.br
}

Ana Paula Lopes da Silva

Universidade Federal de Alagoas, Instituto de Geografia, Desenvolvimento e Meio Ambiente,

Maceió, AL, Brasil

lakes_br@yahoo.com.br

\begin{abstract}
RESUMO - O artigo tem como objetivo discutir os desenhos enquanto recurso didático no ensino de Geografia. Como procedimentos metodológicos utilizou-se de desenhos e justificativas figurativas dos alunos do $6^{\circ}$ ano do ensino fundamental de uma escola pública da cidade de Pilar/Alagoas para viabilizar a análise. As representações dos alunos foram analisadas tanto pela sua forma, quanto pelo conteúdo. A análise da forma (desenho) e conteúdo (justificativas) mostra o entendimento que o alunado tem acerca das relações que possuem com o mundo no lugar (es), as especificidades do(s) lugar (es), e os sentimentos que as pessoas desenvolvem neste(s) espaço(s) e com o outro. Os resultado deste estudo demonstra que os alunos trouxeram fortemente nos desenhos, as relações com o seu cotidiano, destacando a influência da mídia orientando suas concepções, e os sentimentos de pertencimento em relação a rua onde residem.
\end{abstract}

Palavras-chave: Lugar; Representações; Ensino de Geografia.

\section{DRAWING AS A TEACHING RESOURCE IN GEOGRAPHY EDUCATION}

\begin{abstract}
The article aims to discuss drawings as didactic resource in the teaching of Geography. As methodological procedures, the drawings and figurative narratives of 6 th grade students from a public school in the city of Pilar / Alagoas were used to make the analysis viable. The students' representations were analyzed both by their form and their content. The analysis of the form (drawing) and content (narratives) shows the student's understanding of the relationships they have with the world in the place (s), the specificities of the place (s), and the feelings people in this space (s) and the other. The results of this study demonstrate that the students brought strongly in the drawings, the relations with their daily life, highlighting the influence of the media orienting their conceptions, and the feelings of belonging in relation to the street where they reside.
\end{abstract}

Keywords: Place; Representations; Teaching Geography.

\section{INTRODUÇÃO}

O ensino de Geografia possibilita aos discentes e docentes compreenderem a dinâmica do espaço geográfico, suas diferentes categorias e escalas. A leitura e interpretação da dinâmica espacial na escola podem ocorrer por meio de alguns recursos didáticos, dentre eles: desenho, música, produção textual, poesia, maquetes, charges, tirinhas e HQ's (história em quadrinhos). Neste estudo, o desenho e as justificativas dos alunos dos sextos anos são os recursos utilizados. 
Sendo assim, o objetivo deste artigo é analisar os desenhos e as justificativas dos sujeitos da pesquisa, considerando a representação do conjunto de paisagens (conteúdo), no intuito de mostrar que os recursos didáticos utilizados orientam a construção do conceito de lugar.

Trata-se de um estudo de natureza qualitativa e exploratória, os quais foram viabilizados através de um material empírico, a saber: desenhos e justificativas de alunos do sexto ano, de quatro turmas de duas escolas públicas, ambas situadas na cidade de Pilar/AL.

A relevância deste estudo se justifica, na medida em que busca uma possibilidade para a leitura das representações e permite que os alunos do sexto ano possam (re)construir conceitos do seu dia-a-dia, notadamente o conceito de lugar no Ensino de Geografia.

\section{METODOLOGIA}

A metodologia utilizada foi baseada na pesquisa qualitativa, a qual segundo Lüdke \& André (1986, p. 13) é "aquela que envolve a obtenção de dados descritivos, obtidos no contado direto do pesquisador com a situação estudada, enfatiza mais o processo do que o produto e se preocupa em retratar a perspectiva dos participantes", aproximando-se de um determinado foco.

Este estudo é de natureza qualitativa e exploratória, no qual foram coletados duzentos e quarenta e seis desenhos, e duzentas e quarenta e seis justificativas de alunos do sexto ano, de quatro turmas. Essas representações foram realizadas em duas escolas públicas, ambas situadas na cidade de Pilar/AL, totalizando quinhentas e noventa e duas representações.

A cidade de Pilar situa-se no vale do Paraíba e banhada pela laguna Manguaba. Segundo o IBGE (2010) a cidade está a $9^{\circ} 35^{\prime} 49,2^{\prime \prime}$ de latitude sul e $35^{\circ} 57^{\prime} 25,2^{\prime \prime}$, ocupando uma área de aproximadamente 248, $975 \mathrm{~km}^{2}$. Destaca-se que Pilar está situada na Mesorregião do Leste Alagoano, na Microrregião da capital alagoana. As duas escolas selecionadas estão localizadas na cidade de Pilar/Alagoas.

A produção das representações pelos sujeitos desta pesquisa foi orientada através das seguintes questões problematizadoras: $1^{\circ}$ ) Desenhe no verso da folha o que mais gosta na rua onde você mora. Justifique. $2^{\circ}$ ) Desenhe no verso da folha em que rua do município de Pilar/AL você gostaria de morar. Justifique.

Sendo assim, foi criada denominações para os alunos participantes da pesquisa, os quais são destacados pela letra E que significa estudante, junto a uma letra - a, que corresponde a $1^{\circ}$ pergunta problematizadora ou letra - $b$, que corresponde à segunda pergunta, podendo citar como exemplo: (E1-a) que significa Estudante um, questão problematizadora um, ou até mesmo $($ E1-b $)=$ Estudante um, questão problematizadora dois.

As justificativas dos alunos puderam ser interpretadas seguindo uma análise lexical, ou seja, pela repetição de palavras e ideias presentes em seus discursos, levando ao contexto dos lugares onde vivem e desenvolvem suas relações com o mundo.

A análise lexical conforme Chizzotti (2011, p.116) "É uma análise do conjunto das palavras significativas do texto para fazer a mensuração das frequências médias das ocorrências e estabelecer associações relevantes sobre o sentido expresso na mensagem". Desta forma, a repetição das palavras e suas freqüências médias presentes nas narrativas dos alunos levaram a categorização das idéias, significado das mensagens, sendo mensuradas e gerando os dados utilizados no estudo.

Escolhe-se, o sexto ano, porque é neste momento da educação básica que os alunos iniciam o ensino fundamental 2, e que tem a sua disposição professores especialistas na área, no caso especifico, professor de Geografia. Ademais, neste período esses alunos estão discutindo os 
principais conceitos geográficos para entender a dinâmica do espaço, citando: território, região, paisagem e lugar, dentre outros.

\section{RESULTADOS E DISCUSSÃO}

\section{Discutindo o conceito de Lugar}

O lugar na perspectiva crítica é percebido dentro de um processo de formação histórico e cultural que é única. Segundo Carlos (1996, p.9) "o lugar expressa uma manifestação da globalidade, a qual o mundial que existe no local, redefine seu conteúdo sem, todavia anularemse as particularidades", ou seja, o lugar é a base de uma construção social, onde as pessoas desenvolvem uma identidade, entendido como a sede de constantes (re)organizações de forças endógenas e exógenas articuladas.

Um dos caminhos para compreender o lugar está no processo de difusão do meio técnicocientífico-informacional, promovido através das constantes ações internas e externas impostas no(s) lugar(es). A (re)configuração dos lugares é motivada através do sistema produtivo atual na sua busca constante pelo lucro, estando interconectado a velocidade do capitalismo informacional.

Segundo Bauman (2001, p.141) "o capital pode viajar rápido e leve, e sua leveza e mobilidade se tornam as fontes mais importantes de incerteza para todo o resto. Essa é hoje a principal base da dominação e o principal fator das divisões sociais". O processo que Bauman (2001) alerta em sua fala sobre à "leveza", emplementa na atualidade a concentração de renda entre as pessoas e a estruturação de lugares sede da pobreza e da miséria.

A idéia de Bauman (2001) permite pensar que os espaços são construídos através de uma espécie de "molde", arquitetados para atender as necessidades do capital, desconsiderando as especifidades e as necessidades culturais dos diversos grupos sociais locais.

A perspectiva Humanista, denota uma maior importância a palavra lugar em relação a subjetividade que a mesma carrega consigo. Segundo Christofoletti $(1982$, p.22) a perspectiva humanística "Procura valorizar a experiência do indivíduo ou do grupo, visando compreender o comportamento e as maneiras de sentir das pessoas em relação aos seus lugares", valorizando os laços afetivos do indivíduo ou do grupo com os variados componentes materiais do espaço e com as pessoas.

Estima-se que é através dos lugares humanos que se alcança a identidade do lugar pela dramatização das aspirações, necessidades e ritmos funcionais da vida pessoal dos grupos sendo este um mundo de significados organizados (TUAN, 1983). Neste contexto, o lugar é entendido como um conjunto de paisagens que os sujeitos expressam afinidade e executam suas experiências cotidianas, compreendidas através dos vínculos, processos e usos que os homens e as mulheres estabelecem em seus espaços.

Outra característica sobre o lugar na perspectiva Humanística é a identidade, que segundo Holzer (apud RELPH, 1999, p.72) "[...] não pode ser entendida simplesmente em termos de padrão físicos e de traços observáveis, nem só como produtos de atitudes, mas como uma relação condição indissociável destes".

Ademais, o professor Holzer (2000, p.119) destaca que “[...] o lugar é definido como um conjunto complexo, enraizado no passado e incrementando-se com a passagem do tempo, com o acúmulo de experiências e de sentimentos", logo, as extensões do espaço onde os sujeitos se relacionam com as paisagens e pessoas, orientando a construção da identidade em decorrência do tempo, este é o lugar. 
A categoria geográfica lugar, diante da análise Humanística, pode tanto trazer consigo a leitura de mundo vinculada a um sujeito, quanto da coletividade, porque é também através dos conceitos construídos pelas pessoas e de suas lembranças que podemos (re)visitar a história e entender os processos de transformação social e espacial do(s) lugar(es).

Para Mello (2002, p.01) “[...] as lembranças espaciais eternizam-se em nossa memória, os objetos, os homens atribuem significados que são construídos na vivência individual ou dos grupos", logo, podendo reunir registros, interpretações e testemunhos dos diferentes sujeitos, tudo isso, pode ajudar no entendimento da dinâmica socioespacial pertencente ao passado e que faz parte da história que constitui as extensões do lugar, para que assim seja feito um resgate da "memória dos lugares pretéritos" que estão presentes nas pessoas e nos seus objetos sociais.

Os grupos humanos citados por Mello (2002), falam de pessoas em sua vida cotidiana, as quais também se tornam testemunhos do tempo sobre os lugares pretéritos, porque podem trazer a tona fotografias, quadros e até mesmo narrativas (representações) que colaborem para o entendimento da morfologia do conjunto das paisagens locais e os processos que orientam(ram) suas transformações, seguindo este caminho, o lugar será estudado considerando as experiências dos grupos sociais.

Portanto, as diferentes perspectivas geográficas supracitadas nos permitem entender que o lugar é habitual à vida cotidiana, sendo assim, o espaço da experiência em que podemos perceber a dialética do mundo local/global, o qual culturas e mercados se realizam produzindo especificidades. É, nele, onde são reveladas as relações de trabalho, os conflitos sociais, o sentimento que as pessoas possuem sobre aquilo que é seu, desenvolvendo identidade, e, sobretudo, onde as diferentes paisagens são dotadas de significado pelas pessoas.

\section{As representações no estudo do Lugar}

No que diz respeito os desenhos enquanto ferramenta didático-pedagógica, estes podem auxiliar o professor de Geografia em suas aulas, principalmente no momento em que as atividades escolares estejam integradas a construção do conceito de lugar.

Sobre a análise da forma dos desenhos concordamos com Pontuschka (2009, p.292) que "[...] as linhas, formas, superfícies, distâncias, extensões, volumes e suas várias dimensões (comprimento, largura, altura) representam os espaços vividos e as práticas sociais". Neste sentido, a estrutura gráfica possui componentes importantes no que se refere à construção do conceito de lugar.

Para entender o conteúdo dos desenhos utilizamos a ideia de Chizzoti (2006, p.55) que uma das formas de compreendê-lo é "[...] relacionar a frequência da citação de alguns temas, palavras ou idéias em um texto para medir o peso relativo atribuído a um determinado assunto pelo seu autor".

Os dados coletados possibilitaram que fossem detectadas algumas deficiências de aprendizado sobre as relações de proporcionalidade e medida dos desenhos, porque conforme os mesmos e as justificativas produzidas pelos alunos, muitos deles disseram que não conseguiriam representar o conjunto das paisagens da rua onde moravam numa folha de papel.

Nestes termos, a análise das narrativas produzidas pelos alunos, apoia-se em Chizzotti (2006, p.116), na qual através de "uma análise léxica das palavras significativas do texto para fazer a mensuração da frequência média das ocorrências e estabelecer associações relevantes sobre os sentidos expressos na mensagem", proporcionando que os dados coletados fossem lidos e interpretados e, sobretudo, agrupá-los de maneira que pudessem ser preservados seus significados. A figura 1, apresenta três grupos (categorizados) sobre o entendimento do conceito de lugar. 
De acordo com a figura 1, o primeiro grupo, salienta "o lugar enquanto pertencimento", ressaltando que dos cento e vinte seis alunos que participaram da pesquisa, cento e dezesseis representaram a rua onde moram, revelando suas relações de pertencimento, ou seja, às vivências que possuem com os moradores da localidade e justificando a necessidade da localização de sua morada, por conta do laço que possuem com a família ou com os amigos.

Figura 1. Percepções de alunos do sexto ano de escolas públicas de Pilar/AL sobre Lugar.

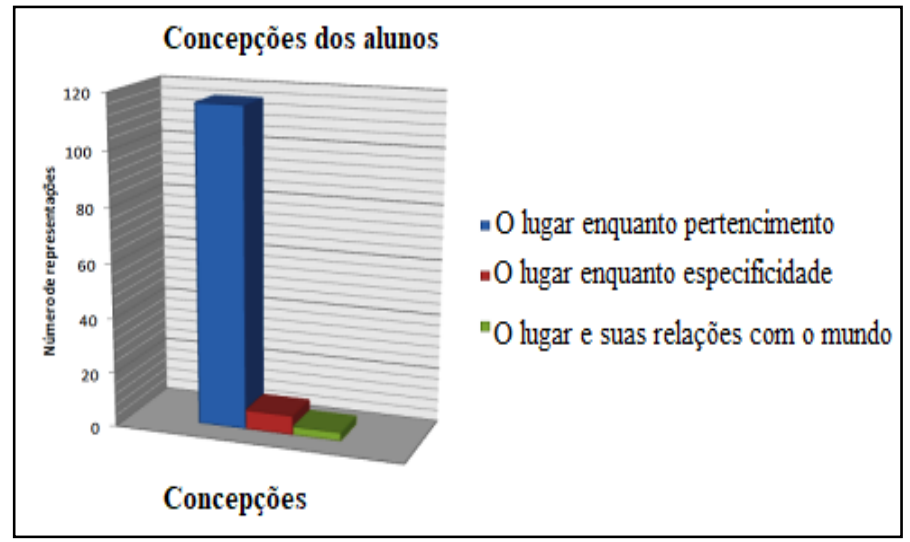

Fonte: DANTAS, (2012).

Neste contexto, foi selecionada uma representação (Figura 2), a qual denota uma quantidade significativa de elementos textuais e traços, em relação ao sentimento que os sujeitos possuem com os outros sujeitos e a rua em que vivem, sendo utilizado o mesmo procedimento para os demais grupos, porém levando em consideração suas caracterizações.

Figura 2.

gráfica de alunos escolas públicas

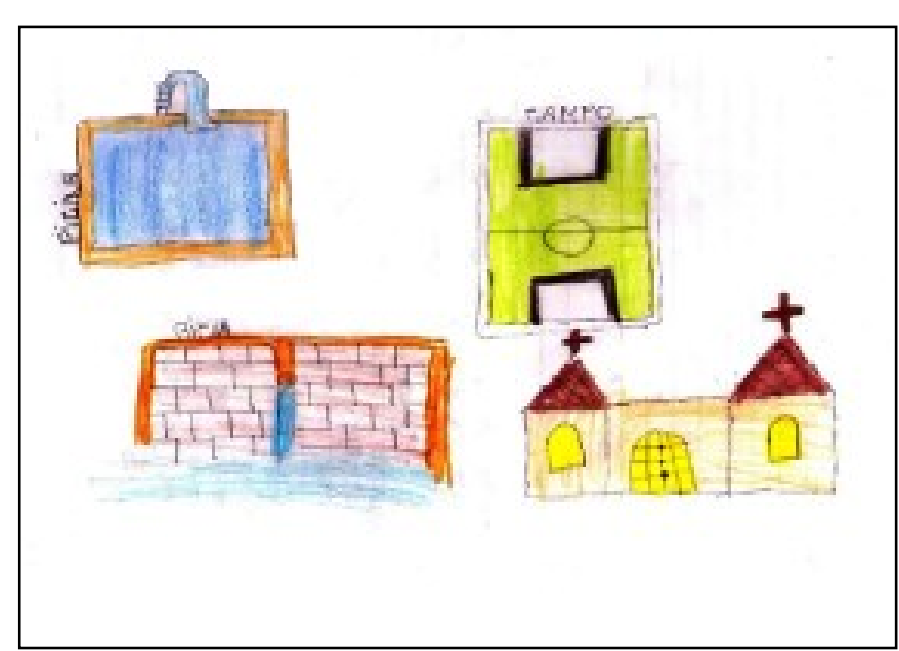

Representação do sexto ano de de Pilar/AL.

Fonte: DANTAS, (2012).

De acordo com a figura 2 se observa um conjunto de paisagens que possui afinidade demonstrando a bica, a piscina, o campo de futebol e a igreja, percebendo-se a última por conta das duas cruzes simbolizadas no desenho e porque a mesma é reafirmada em sua justificativa. 
Nas representações do aluno E1-a, se percebe a dimensão do cotidiano contribuindo para o entendimento do lugar. A fala do aluno reitera a afirmação: "Eu gosto de onde eu moro por que eu tomo todo dia banho na piscina E depois que eu saio da piscina eu vou jogar bola mais os meus irmãos e depois a gente vai para casa e vai tomar banho na bica agente gosta de mora lá por que é tudo calmo só tem zuada quando é dia de sábado e domingo. Eu gosto de ir as missas nos dias de domingos lá na Igreja, é muito bom morar lar".

A leitura do cotidiano segundo a professora Heller (1970) nos leva a pensar sobre a vida cotidiana que é comum a todos os homens, os quais devem aprender a conviver com as atividades diárias no sentido de que possam se construir enquanto cidadãos.

A justificativa do aluno E1-a também ressalta o sentimento de pertencimento e as principais atividades que o sujeito desenvolve na rua onde mora, denotando bem estar, afeição e lazer. Conforme Holzer (apud RELPH, 1999, p.06) "[...] a essência do lugar é a de ser o centro das ações e das intenções, onde são experimentados os eventos mais significativos de nossa existência", assim o lugar deve ser compreendido através das idéias e ações dos indivíduos que o constrói socialmente, permitindo revelar tanto os laços de identidade que as pessoas possuem com os ambientes, quanto às contribuições dos indivíduos na dinâmica socioespacial.

O segundo entendimento acerca do conceito de lugar, conforme a figura 1, compreende: "o lugar enquanto especificidade", o qual evidencia o acesso e a proximidade dos equipamentos urbanos, os quais podem facilitar a vida cotidiana deles, como por exemplo, a qualidade das vias asfaltadas, o acesso as escolas, aos campos de futebol, as praças e até mesmo aos postos de saúde, citando também a Laguna Manguaba como uma fonte de renda em relação a pesca.

O aluno E20 representa a Rua Nicolau Mota, mostrando algumas singularidades da mesma, como exemplo, a Laguna Manguaba e também o uso que os moradores fazem dela com a atividade da pesca, como pode ser visto na figura 3.

Figura 3. Representação gráfica de alunos do sexto ano de escolas públicas de Pilar/AL.

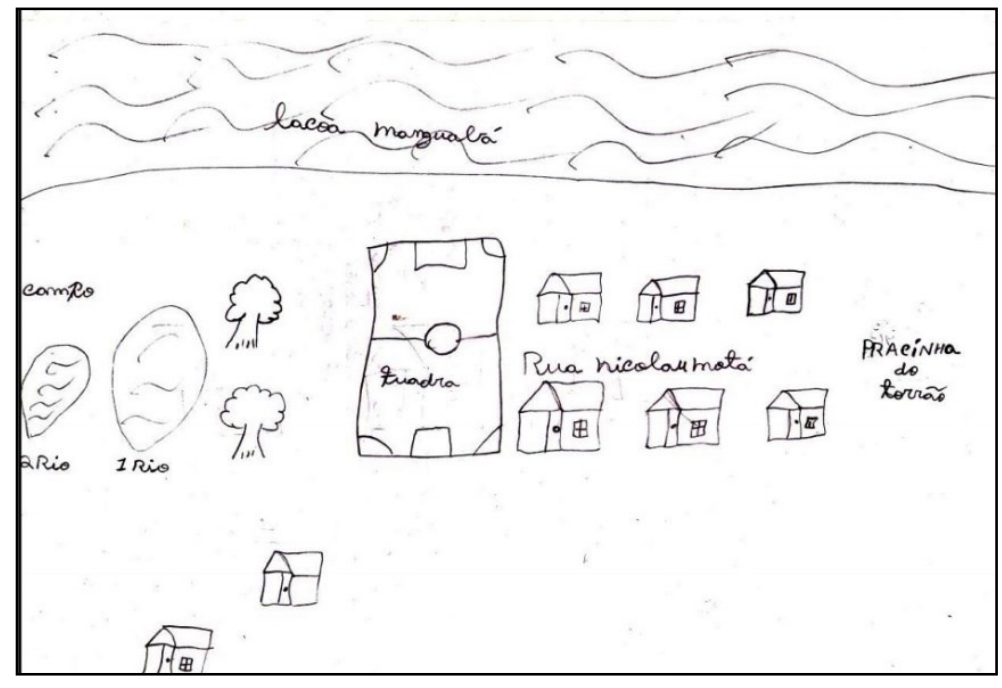

Fonte: DANTAS, (2012).

A figura 3 destaca a existência de oito casas, na parte central e inferior, dois campos de futebol, no centro e margem esquerda, duas árvores e dois rios, na mesma margem dos campos, uma praça, margem direita, e o nome da laguna que banha a cidade, Manguaba, no extremo superior, uma rua, Nicolau Mota, e praça, intitulada pracinha do Torrão situada na extremidade direita. 
Outra característica importante percebida na narrativa de E20 é a inabilidade sobre as medidas, a qual foi manifestada na justificativa de um dos alunos durante a aplicação da atividade, podendo ser lida a seguir: "Olha professor! Desenhei a Rua Nicolau Mota, a Praça Ana Genilda, mas nesta folha não da para desenhar o campo que jogo bola que fica aqui do lado de minha casa, veja só professor, a folha é muito pequena, fiz o rio 1, o rio 2 a lagoa e a pracinha do Torrão também".

Em relação ao conjunto de paisagens representadas na figura 2, realizadas pelo aluno E20-a em relação à Rua Nicolau Mota e a laguna, denota-se o significado através da seguinte afirmação: "gosto da rua onde eu moro por que lá tem dois rios onde eu passo mi diverte ainda tem a lagoa que serve de fonte de renda para os moradores da rua é por isso que eu gosto da onde eu moro".

$\mathrm{O}$ aluno E20 - também enfatiza a atividade pesqueira existente no lugar e revela que se utiliza dos rios como espaço de lazer, os quais são citados no desenho como: o Rio 01 e o Rio 02. Na perspectiva de Carlos (1996, p.18) "[...] o lugar é a porção do espaço apropriável para a vida apropriada através do corpo - dos sentidos - dos passos de seus moradores", desta forma, podemos compreender que ao instante que os homens se relacionam com o mundo e dota de significado um conjunto de paisagens, este é o lugar.

O aluno E20 quando foi convidado a desenhar a rua onde mora, através das problematizações, o mesmo não ficou atento para as dimensões que estava representando. Entretanto, a intenção deste não se trata de entender a área, escalar ou qualquer linguagem matemática e, sim, revelar os significados que os sujeitos atribuem ao lugar.

No que se refere ao terceiro grupo: "o lugar e suas relações com o mundo", três alunos expressaram uma aversão à rua e a cidade em que moram declarando suas preferências em residir na Bahia, em París, e até no Havaí ao invés da cidade Pilar.

O aluno E43 ressalta:"Eu queria morar em Paris. para ir Para praias chiques conhecer famosos e me diverti". A vontade de morar em outros países e até mesmo em outras cidades brasileiras também se manifestou nos demais alunos deste grupo, os quais justificaram que através da mídia puderam perceber as melhores condições socioeconômicas. Assim como, o acesso à saúde e a educação pública de qualidade, a moradia e a empregabilidade.

A figura 4 apresenta uma torre, um rio, um Sol, um conjunto de nuvens e o céu azulado. Nesta, a torre não possui uma base, aparentando que está levitando e a nuvens aparentam estar se movimentando na direção contrária do Sol. O desenho possibilita entender que se trata da cidade de Paris, a qual esta sendo representada, confirmando essa hipótese através de sua justificativa.

A justificativa apresentada pelo aluno E41-b justifica o porquê e onde apreendeu que a cidade de Paris tem muitas praias chiques, possui muitas pessoas famosas, têm uma quantidade significativa de sujeitos educados e que não jogam papel no chão, está a seguir: - ah! professor eu assisti no Programa xxx da televisão que a cidade de Paris é desse jeito mesmo, assim quero morar lá e não aqui", referindo-se a Pilar.

Conforme Bauman (1998, p.62) “[...] os habitantes locais encontram os globais através das transmissões regulares do céu pela TV. Os ecos do encontro reverberam globalmente, abafando todos os sons locais". As pessoas são constantemente bombardeadas de informações sobre questões socioeconômicas ou até mesmo socioambientais dos diversos lugares do mundo através dos meios de comunicação em massa, neste sentido, as necessidades locais são ofuscadas pelo brilho da mídia. 
Já Santos (2012, p.173) afirma que “[...] a informação unívoca, obediente às regras de um ator hegemônico, introduz, no espaço, uma intervenção vertical, que geralmente ignora o seu entorno, pondo-se ao serviço de quem tem os bastões de comando", logo, as pessoas são informadas constantemente sobre os hábitos lucrativos da globalidade, dessa maneira, o que vem de fora, como por exemplo, a moda ou até mesmo as tecnologias podem contribuir para construção das concepções de mundo dos sujeitos.

Figura 4. Representação gráfica dz alunos do sexto ano de escolas públicas de Pilar/AL.

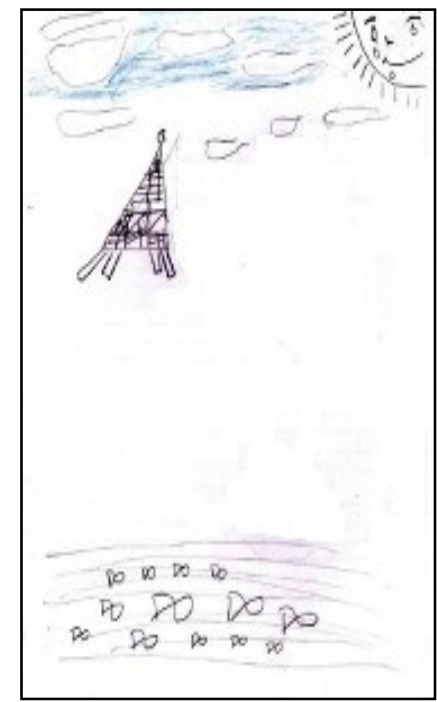

Fonte: DANTAS, (2012).

A justificativa do aluno E43 nos leva a refletir sobre o meio técnico-científico e informacional, neste caso, a televisão, meio de comunicação em massa, transmitindo um programa de entretenimento, o qual consegue condicionar as representações do aluno, ao desenhar a torre Eiffel e o Rio, deduzido como o Rio Sena. Na figura 3 evidenciada anteriormente, e sua justificativa, visto que o referido programa foi mencionado como fonte de inspiração durante a produção de suas representações.

\section{CONSIDERAÇÕES FINAIS}

Este artigo demonstra que a escola é o lócus para o professor pesquisador aguçar constantemente a sua prática socioeducativa e dinamizar o processo de ensino-aprendizagem, através de recursos didáticos que possam instigar os alunos a participarem ativamente do processo de construção do conhecimento.

As análises das representações dos alunos demonstraram que nas aulas de Geografia os desenhos se tratam de importantes instrumentos para a leitura socioespacial, sendo de extrema relevância que se considere ainda as justificativas, tendo em vista que o desenho é um instrumento bastante subjetivo, e, portanto, as justificativas podem expressar o entendimento do sujeito que os produziu.

Os desenhos enquanto recurso didático possibilitou os alunos resgatar a memória e os mesmos representaram os vários conjuntos de paisagens que compõem a cidade de Pilar/AL, tomando como ponto de partida a rua onde moram e principalmente revelando suas leituras de mundo. 
A respeito das justificativas produzidas pelos alunos, as mesmas representam um momento da leitura do espaço geográfico segundo os mesmos e, sobretudo, conceitos construídos pelos mesmos em sua cotidianidade. As justificativas permitem aos professores criarem cada vez mais problematizações ligadas ao espaço apropriado e produzido pelos alunos, a fim de estimulá-los tanto na produção de texto, quanto entender a configuração social dos lugares, neste caso na cidade de Pilar/AL.

Os alunos trouxeram na maioria das justificativas e de seus desenhos detalhes voltados a identidade que possuem com o lugar e com as outras pessoas; considerando também as especificidades locais e a dimensão da globalidade. Entretanto, o recorte de maior evidência expresso pelos alunos foi em relação ao sentimento de pertencimento, porque dos cento e vinte e três participantes deste estudo, cento e dezesseis se relacionam com o grupo intitulado: o lugar enquanto pertencimento, o qual foi interpretado seguindo leituras da perspectiva humanística.

A categoria de análise geográfica lugar, explorada neste estudo, através das representações trouxe consigo afirmações e traços, forma-conteúdo, os quais foram além da mera descrição da paisagem, ou seja, o traçado e os textos expressam sentimentos; conexões dos espaços representados que pertencem com o mundo e algumas singularidades da cidade, obviamente considerando o recorte da rua onde cada aluno mora.

As considerações supracitadas só reafirmam a importância de utilizar recursos didáticos desta natureza nas aulas de Geografia, neste caso, o desenho sendo produzido através de questões problematizadoras. Mediante a isso deve ser colocado que o processo de construção dos instrumentos, formulação e resolução das problematizações quebram a rotina cotidiana e torna a sala de aula um espaço solidário, tendo como função principal promover o protagonismo dos discentes em relação a construção de conhecimentos.

Deve ser salientado também que as representações produzidas pelos sujeitos da pesquisa, só puderam ser analisadas considerando seus aspectos particulares e gerais, concebidas como ícones que se repetem ou como relações que podem ser tecidas e interpretadas, forma-conteúdo.

Por fim, a utilização das representações no ensino de Geografia, como um recurso didáticopedagógico nas aulas de Geografia, revela as concepções de mundo dos alunos que participam do seu processo de produção, estimulando-os a partir da aplicação de novas atividades e criação de problematizações o amadurecimento de conceitos trazidos de sua cotidianidade, aguçando a percepção deles sobre o espaço geográfico.

\section{REFERÊNCIAS}

BAUMAN, Zygmunt. Globalização as consequências humanas. Rio de Janeiro: Zahar, 1998.

. Modernidade Líquida. Rio de Janeiro: Zahar, 2001.

CARLOS, A. F. O Lugar no/do Mundo. São Paulo: Hucitec,1996.

CHIZZOTTI, Antonio. Pesquisa qualitativa em ciências humanas e sociais. Vozes: Rio de Janeiro, 2011.

CHRISTOFOLETTI, Antonio. Perspectivas da geografia. São Paulo: DIFEL, 1982.

HELLER, Agnes. O cotidiano e a história. $6^{\circ}$ ed. São Paulo: Paz e terra, 1970.

HOLZER, Werther. Memórias de Viajantes: Paisagens e Lugares de Um Mundo Novo. GEOgraphia Revista do Programa de Pós-Graduação em Geografia da Universidade Federal Fluminense. n. 3, p.67-78, ano. II. 2000.

O lugar na geografia humanista. Revista Território. Rio de Janeiro, n 7, p. 67-78, jul./dez. 1999. 
LUDKE, Menga. ANDRE, Marli E. D. A. de. Pesquisa em Educação: abordagens qualitativas. São Paulo: EPU, 1986.

MELLO, João Baptista Ferreira. Restauração dos lugares passados. Revista do Departamento de Geografia, UERJ. Rio de Janeiro, n.12, p.63-68, segundo semestre de 2002.

SANTOS, Milton. A Natureza do Espaço: técnica e tempo, razão e emoção. $4^{\circ}$ ed. São Paulo: Edusp, 2012.

TUAN, Yi-Fu. Espaço e Lugar: a perspectiva da experiência. São Paulo: DIFEL, 1983. 